\title{
Vertalen in het vreemdetalenonderwijs? Studenten aan het woord...
}

\section{Student perspectives on translation in foreign language teaching}

\author{
Muriel Waterlot
}

\begin{abstract}
In recent years there has been a reassessment of the role of translation and translations in foreign language teaching and education (Cook, 2010; Laviosa, 2014; Carreres, 2014). Nowadays the Common European Framework (2001) recognizes translation and interpretation as a language activity which is called 'mediation'. Because of the lack of descriptors, these activities seem nevertheless still largely overlooked. In addition, a study by the European Union on the role of translation in the teaching of languages in the EU revealed the need for greater understanding of the views of students in the learning of foreign languages (Pym, Malmkjær and Gutiérrez-Colon, 2013). In order to meet this requirement, this paper reports on the opinion of Polish students on translation in foreign language education. Based on the findings of a translation project realized in the master's program at the John Paul II Catholic University of Lublin, it also examines their views about working with real translation assignments.
\end{abstract}

\section{Keywords}

translation, foreign language teaching, foreign language education (FLE), translation didactics, language teaching, didactics. 


\section{Inleiding}

In de afgelopen jaren heeft een herwaardering plaatsgevonden van de rol van vertalen en vertalingen in het taalonderwijs (Cook, 2010; Laviosa, 2014; Carreres, 2014). Een bewijs hiervan is het feit dat de Raad van Europa in 2001 in zijn Europees Referentiekader vertalen en tolken vermeldt waarnaar wordt verwezen met de term mediation of 'bemiddeling' (CEFR 2001: 14) (ERK 2008: 17)1. Dit betekent dat de Raad - naast activiteiten van receptie, interactie en productie (schriftelijke en mondeling) - het vertalen voortaan ook als een volwaardige taalactiviteit erkent. Volgens het ERK kan het meer bepaald worden ingezet als een didactisch instrument om specifieke competenties, zoals de interculturele competentie en de communicatieve taalcompetenties, van taalleerders te bevorderen (ERK 2018: 13, 98). Het gebrek aan descriptoren voor deze taalactiviteit in de publicatie van de Raad van Europa uit 2001 heeft er echter toe geleid dat de zogenaamde 'bemiddelingsactiviteiten' in taallessen nog steeds over het hoofd worden gezien. In 2017 publiceerde de Raad van Europa een supplement van het ERK met nieuwe descriptoren en beoordelingsschalen voor bemiddelingsactiviteiten (CEFR 2017). De Nederlandse vertaling van dit document verscheen in december 2019 onder de naam Gemeenschappelijk Europees referentiekader voor moderne vreemde talen: leren, onderwijzen, beoordelen. Supplement met nieuwe descriptoren (ERK 2019). De schalen voor bemiddeling worden er weergegeven in drie groepen die weerspiegelen op wat voor manier bemiddeling meestal voorkomt: 1) bemiddeling van een tekst; 2) bemiddeling van concepten ; 3) bemiddeling van communicatie (ERK 2019: 99). Het schriftelijke en mondelinge vertalen van een tekst valt onder punt 1: bemiddeling van een tekst en houdt in dat "de inhoud van een tekst waartoe deze persoon geen toegang heeft, vaak als gevolg van linguïstische, culturele, semantische of technische barrières, wordt doorgeven aan een andere persoon.” (ERK 2019: 99). Deze betekenis komt overeen met de betekenis van de term 'bemiddeling' in het ERK dat in 2001 verscheen (cfr. CEFR 2001 of ERK 2008). Onder de bemiddeling van concepten worden activiteiten vermeld zoals bijvoorbeeld het samenwerken in een groep, het samenwerken aan betekenisvorming, het leiden van groepswerk en het aanmoedigen van de conceptuele dialoog (ERK 2019: 99). Tot slot worden onder de bemiddeling van communicatie activiteiten genoemd zoals het optreden als intermediair in informele situaties (met vrienden en collega's), het mogelijk maken van communciatie in gevoelige situaties en bij onenigheid (ERK 2019: 99).

Het rapport Translation and language learning: The role of translation in the teaching of languages in the European Union van het 'Directorate General' van de Europese Commissie van 2013 (Pym, Malmkjær and Gutiérrez-Colon, 2013), wees op de behoefte aan meer inzicht in de mening van studenten met betrekking tot de rol van vertalen en vertalingen in het taalonderwijs:

1 De Nederlandse vertaling van het Common European Framework of Reference for Languages (CEFR) van de Raad van Europa werd uitgegeven in 2008 onder de naam Gemeenschappelijk Europees Referentiekader voor Moderne Talen (hierna afgekort met ERK). 
There are several aspects that we would have liked to investigate further, and which should be dealt with in future projects:

1. The student's perspective: The severe time restriction on our research did not allow us to gather data on the use of translation from the perspective of the student's experience, both socially (classroom interaction and motivation) and cognitively (eye-tracking). The existing studies on this (see 2.2.2) generally indicate high levels of involvement and motivation associated with translation activities, but we would like to know more about how students react to specific kinds of translation tasks (Pym, Malmkjær en Gutiérrez-Colon, 2013: 136). [eigen vetdruk, MW]

Om tegemoet te komen aan deze behoefte werden met behulp van een enquête gepeild naar de mening van studenten omtrent het vertalen als werkmethode in het Nederlandse vreemdetalenonderwijs onder de studenten van het eerste jaar van de masteropleiding. Tijdens de vertaalcolleges werkten de studenten aan een reële vertaalopdracht (zie punt 3 voor meer details). Bijgevolg werd in de vragenlijst ook gepeild naar hun mening omtrent het werken met dit soort vertaaltaken. Dit artikel brengt verslag uit van de kwalitatieve en kwantitatieve gegevens van deze vragenlijst. Eerst worden het theoretisch kader van dit onderzoek toegelicht (cfr. punt 1). Daarna worden de onderzoeksvragen geformuleerd en wordt de methodologie gepresenteerd (cfr. punt 2 en punt 3). Tot slot worden met behulp van diagrammen de onderzoeksresultaten voorgesteld (cfr. punt 4). Het artikel wordt afgerond met een conclusie (cfr. punt 5).

\section{Theoretische achtergronden}

De theoretische basis die aan de grondslag ligt van de didactische aanpak van de praktische vertaalcolleges (en in dit kwantitatieve onderzoek wordt geëvalueerd), steunt op drie pijlers: 1) het sociaal constructivisme, 2) de functionele Ẽ taakgerichte aanpak en 3) de communcatieve vertaling.

Het sociaal constructivisme is een leerfilosofie die het leren beschouwt als een sociaal en collaboratief proces waarbij de leerders - elk met hun eigen idiosyncratische behoeften en achtergronden - hun kennis opbouwen via de interactie met 'medeleerders' en docent en via de taken zelf (Lantof 2000). Het taakgericht onderwijs vindt anders gezegd haar oorsprong in het sociaal-constructivisme (Van Kalskbeek 2005: 65). Een voorstander deze aanpak is de vertaalwetenschapper Don Kiraly die in zijn werk A Social Constructivist Approach to : Translator Education, Empowerment from Theory to Practice (2000) pleit voor reële vertaalopdrachten in vertalersopleidingen, waarbij de docent optreedt als bemiddelaar tussen een reële opdrachtgever op de markt en de studenten als uitvoerders van een vertaalopdracht. Werken met reële vertaalopdrachten biedt vooral het voordeel dat studenten de verschillende stadia van de uitvoering van een vertaalopdracht of -project doorlopen zoals dat in de realiteit gebeurt. De opdracht waarin de studenten hebben gewerkt, ligt dus in de lijn Kiraly's didactische aanpak oftewel de zogenaamde Social Contructivist Approach en beoogde de studenten in contact te brengen met de wereld van 
de professionele vertaling. Het concept van de zogenaamde learner empowerment staat hierbij centraal. Kiraly (2000) definieert de term 'empowerment' als volgt:

Attaining competence in a professional domain means acquiring the expertise and thus the authority to make professional decisions; assuming responsibility for one's actions; and achieving autonomy to follow a path of lifelong learning (Kiraly 2000: 1).

Uit deze definitie van 'empowerment' blijkt het belang van het autonoom nemen van beslissingen en het dragen van verantwoordelijkheid voor eigen handelen van de leerders. Die nemen een centrale plaats in in het leerproces.

In de context van de vertaaldidactiek in het vreemdetalenonderwijs wordt in de functionele $\mathcal{E}^{2}$ taakgerichte aanpak een vertaaltaak, die ontleend wordt aan een gegeven doelsituatie, gerealiseerd door de taalleerder. Hierbij speelt de leerder de rol van zowel ontvanger als zender van een boodschap (brontekst en doeltekst) die bij het vertalen (of bemiddelen) niet langer de betekenis van de boodschap maar de functie ervan vooropstelt (Waterlot 2018).

Onder het begrip communicatieve vertaling verstaan we tot slot een taalactiviteit die de actieve interactie tussen de docent en de studenten ontlokt en die zinvol is voor de studenten. Dit begrip zal hier dus niet gelinkt worden aan de definitie van Hervey et al. (1995: 24) die communicatieve vertaling beschouwt als vertaaloplossing voor cultureel conventionele formules waarbij een letterlijke weergave ongepast zou zijn ["culturally conventional formulas where a literal rendering would be inappropriate"].

\section{Onderzoeksvragen:}

Bij aanvang van dit onderzoek werden de volgende onderzoeksvragen geformuleerd:

- Wat is de opinie van studenten over:

- vertalen en vertalingen in het vreemdetalenonderwijs;

- het werken met reële vertaalopdrachten in de vreemdetaalles.

- Wat we kunnen leren van de opinie van studenten hierover.

\section{Methodologie:}

Om de onderzoeksvragen te beantwoorden maakte ik gebruik van een enquête met vragen over de mening van studenten omtrent vertalen en reële vertaalopdrachten in taalverwerving.

De vragenlijst werd na het beëindigen van de vertaalopdracht ingevuld door 17 studenten van het eerste jaar van de masteropleiding.

De vertaalopdracht bestond uit de vertaling van de script van de documentaire « Zie mij doen » van Klara Van Es over mensen met een verstandelijke beperking. De film won de prijs voor Beste Belgische documentaire op Docville in 2018. 
Didactisch werden de drie theoretische pijlers (die werden beschreven in punt 1) in de praktijk als volgt gerealiseerd:

- In de lijn van de functioneel en taakgerichte aanpak werd de groep van 17 studenten verdeeld in vier kleinere groepen. In elke groep werden twee hoofdcoördinatoren aangeduid die - in de hoedanigheid van bemiddelaars tussen de studenten en de docent - per e-mail elk van de studenten twee opdrachten stuurden: 1) een vertaalopdracht waarbij elke student een deel van de script naar het Pools moest vertalen en 2) een 'feedbackopdracht' waarbij aan elke student (eerst schriftelijk en daarna mondeling) werd gevraagd om feedback te geven op de vertaling van een student van een andere groep.

- Omdat het om een reële vertaalopdracht ging met een reële deadline, werd - in de lijn van het sociaal constructivisme - gewerkt met een kalender met stricte deadlines voor het inleveren van vertalingen en feedback.

- In de lijn van de communicatieve vertaling (communicative translation) kregen de studenten de opdracht om tijdens de vertaalcolleges hun feedback mondeling te presenteren aan de groep, en hun vertaaloplossingen te verantwoorden en klassikaal te bespreken (met docent en medestudenten).

De enquête werd met het gratis onlineprogramma 'survio' samengesteld en bestond in totaal uit dertien vragen. De eerste reeks vragen houdt verband onder andere met de mening van de taalleerders met betrekking tot het vertalen en het vertalen als middel om een vreemde taal te leren, en de tekstsoorten die ze graag zouden willen vertalen (vraag 1 tot 6). In de tweede reeks vragen wordt gepeild naar hun mening omtrent het nut de vertaalcolleges (filmvertaling), de feedbacksessies en het werken met een reële vertaalopdracht (vraag 7 tot en met 13).

\section{Onderzoeksresultaten}

In vraag 1 werden de studenten gevraagd om de volgende stelling te beoordelen:

1. Vertalen moet worden gedoceerd in de masterfase van een filologische opleiding als onderdeel van een taal(verwervings)cursus.

Op deze vraag antwoordden alle studenten (100\%) unaniem 'ja'.

De volgende twee vragen (cfr. vraag 2 en vraag 3 ) en hielden verband hun voorkeur voor de vertaalrichting:

2. Vind je vertalen uit het Nederlands naar het Pools leuk?

Voor deze vraag maakten we gebruik van een 10-punts Likert-schaal waarbij 1 stond voor 'helemaal niet leuk' en 10 voor 'erg leuk'. De meerderheid beantwoordde deze vraag met een $8 / 10$ (cfr. diagram 1 ).

3. Vind je vertalen uit het Pools naar het Nederlands leuk?

Ook voor deze vraag maakten we gebruik van een Likert-schaal (10-punts). Het gemiddelde voor deze vraag bedroeg $7 / 10$ (cfr. diagram 1). 


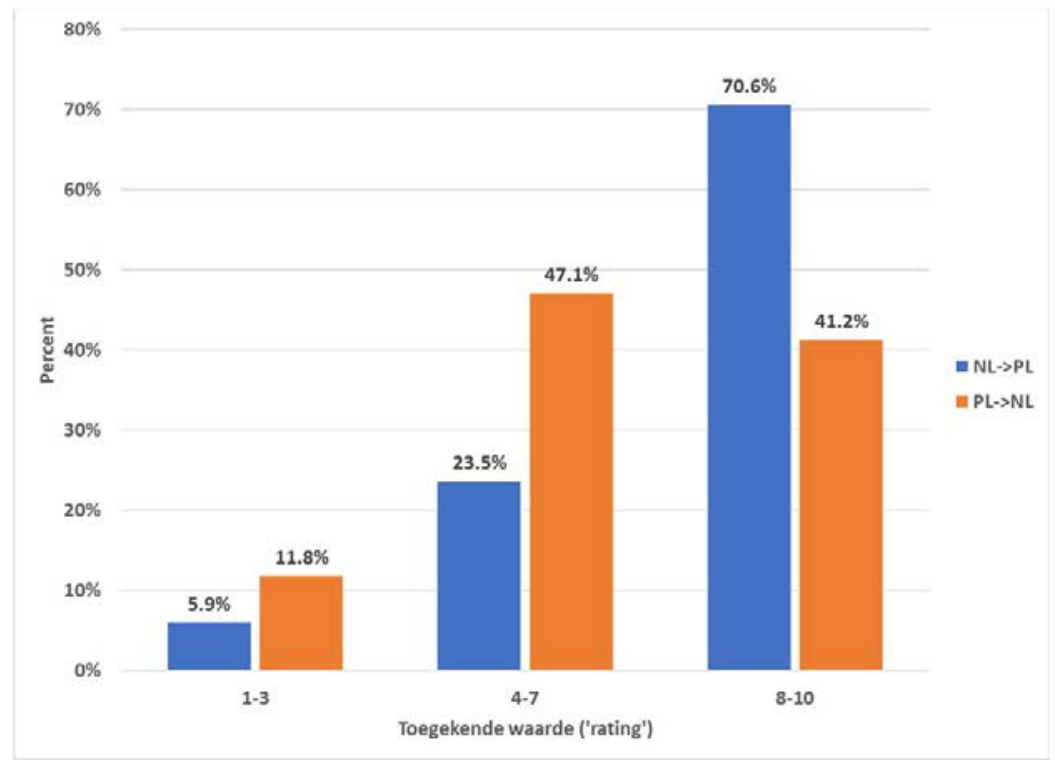

Diagram 1: voorkeur vertaalrichting

Uit het bovenstaande diagram (cfr. diagram 1) waarin we de antwoorden van zowel vraag 2 als vraag 3 hebben gegroepeerd, kunnen we afleiden dat de studenten liever vertalen van het Nederlands naar het Pools. Dit resultaat houdt verband met het feit dat vertalen naar het Nederlands voor hen moeilijker is. Uit dit resultaat kan niettemin ook worden geconcludeerd dat ze vrij graag vertalen naar het Nederlands.

In vraag 4 peilden we naar hun belangstelling om later als vertaler te werken :

4. Zou je later graag een professionele vertaler willen worden?

$76,5 \%$ beantwoordde deze vraag met 'nee', $17,6 \%$ met ja en 5,9\% met 'weet het niet'. Uit deze antwoorden blijkt dat de meerderheid van de studenten die aan dit onderzoek heeft deelgenomen, later niet als vertaler wil werken.

De volgende twee vragen (cfr. vraag 5 en vraag 6 ) hielden verband met de tekstoorten die de studenten graag zouden willen vertalen (uit en naar het Pools). Om gemakkelijker vergelijkingen te maken, werden de resultaten van beide vragen opnieuw opgenomen in een enkel diagram (cfr. diagram 2).

5. Welke 'tekstsoorten' zou je tijdens de vertaallessen willen vertalen uit het Pools naar het Nederlands?

De resultaten op deze vraag, die gevisualiseerd worden in diagram 2, tonen aan dat de meerderheid graag filmscripts en games (computerspellen) wil vertalen (cfr. 64,7\%) (cfr, diagram 2). Dat leverde ons het bewijs dat ze graag aan de vertaling van de filmscript hebben gewerkt. Literaire teksten en gedichten scoorden het laagst met $5,9 \%$. 
6. Welke 'tekstsoorten' zou je tijdens de vertaallessen willen vertalen van het Nederlands naar het Pools?

Uit diagram 2 kan worden afgeleid dat de voorkeur van de studenten in dit geval uitgaat naar de vertaling van artikels uit kranten en tijdschriften en zakelijke teksten. Het minst hebben ze belangstelling voor de vertaling van gespecialiseerde teksten (uit rechtspraak, economie, wetenschap en techniek) (11,8\%) (cfr. diagram 2).

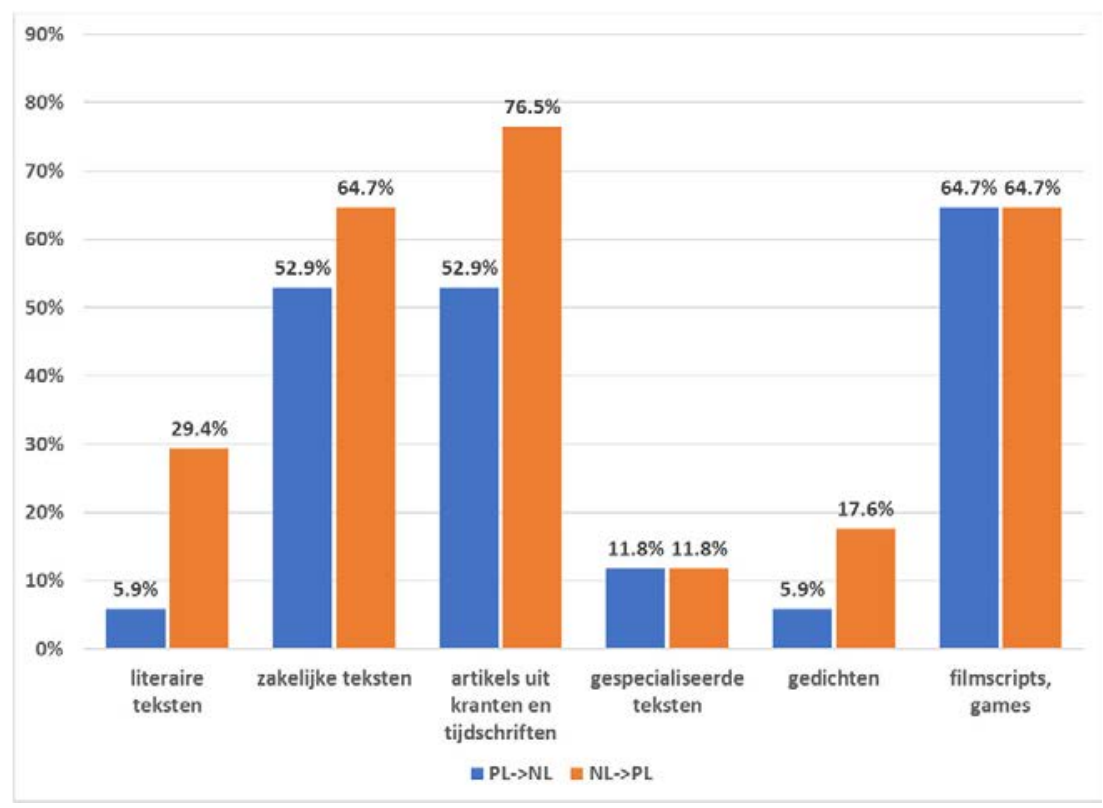

Diagram 2: voorkeur tekstsoorten

7. In vraag 9 vroegen we de studenten om eventuele opmerkingen/adviezen te noteren met betrekking tot vertalen als middel om een vreemde taal te leren. Op deze vraag ontvingen we onder meer de volgende commentaren:

- Vertaling kan helpen een cultuur en woordenschat van een andere taal te ontdekken. Dat vind ik nuttig. We kunnen ook verschillen tussen twee talen zien.

- Woordenschat en schriffuaardigheid

- Het is een goede techniek voor het leren van nieuwe woorden

- Zelf vind ik vertalingen in het proces van de tweedetaalverwerving nuttig, in het bijzonder het opbouwen van vocabulaire en leren hoe het taalsysteem in het Nederlands werkt.

- Studenten kunnen op die manier beter uitdrukkingen uit gewone gespreken leren kennen.

- Het vertalen is nuttig voor de kennis van woordeschat en zinsbouw.

Uit deze antwoorden konden we afleiden dat volgens de studenten vertalen vooral nuttig is voor het verrijken van hun kennis van de Nederlandse woordenschat en grammatica (zinsbouw). 
De volgende twee vragen (cfr. vraag 9 en vraag 10) hielden verband met de mening van de studenten omtrent het nut ('bruikbaarheid') van de filmvertaling om Nederlands te leren, en de gebieden waarin ze denken dat ze vooruitgang hebben geboekt. De antwoorden op deze twee vragen groepeerden we in diagram 3.

8. Hoe nuttig was het vertalen van de film 'Zie mij doen' uit het Nederlands naar het Pools als middel om Nederlands te leren?

De meerderheid gaf een $7 / 10$ voor deze vraag en vond de vertaalopdracht een vrij goede manier om Nederlands te leren (cfr. diagram 3).

9. Kruis de gebieden aan waarin de vertaling van 'Zie mij doen' uit het Nederlands naar het Pools je hebben geholpen vooruitgang te boeken: de domeinen 'woordenschat' (cfr. 70,6\%) en 'registers in het Nederlands'(cfr. 52,9\%) scoorden voor deze vraag het hoogst. Ook de kennis van de broncultuur (Vlaanderen) scoorde vrij hoog met 23,5\% (cfr. diagram 3).

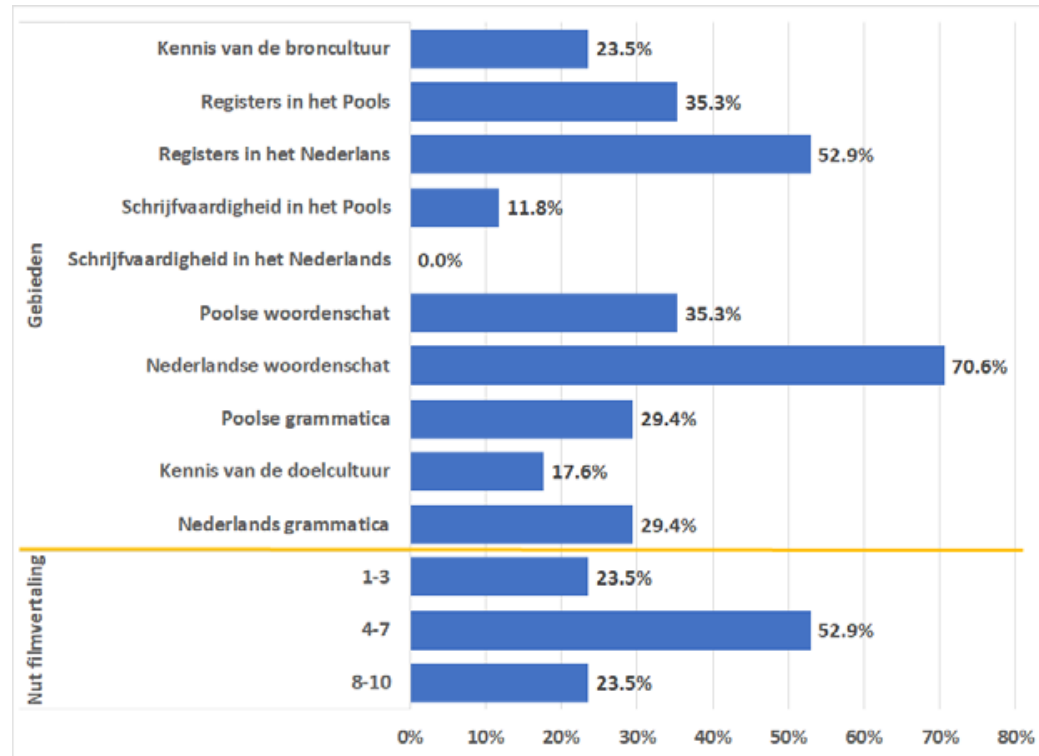

Diagram 3: filmvertaling : nut en vooruitgang per domein (gebied)

De volgende vraag hield verband met de feebacksessies en het nut ervan om vorderingen te maken in bepaalde domeinen :

10. Kruis de vaardigheden aan waarin de feedbacksessies je hebben geholpen vooruitgang te boeken.

Op deze vraag scoorden vooral de 'spreekvaardigheid' (58.8\%) en de 'vertaalvaardigheid' (40\%) het hoogst (cfr. diagram 4). 


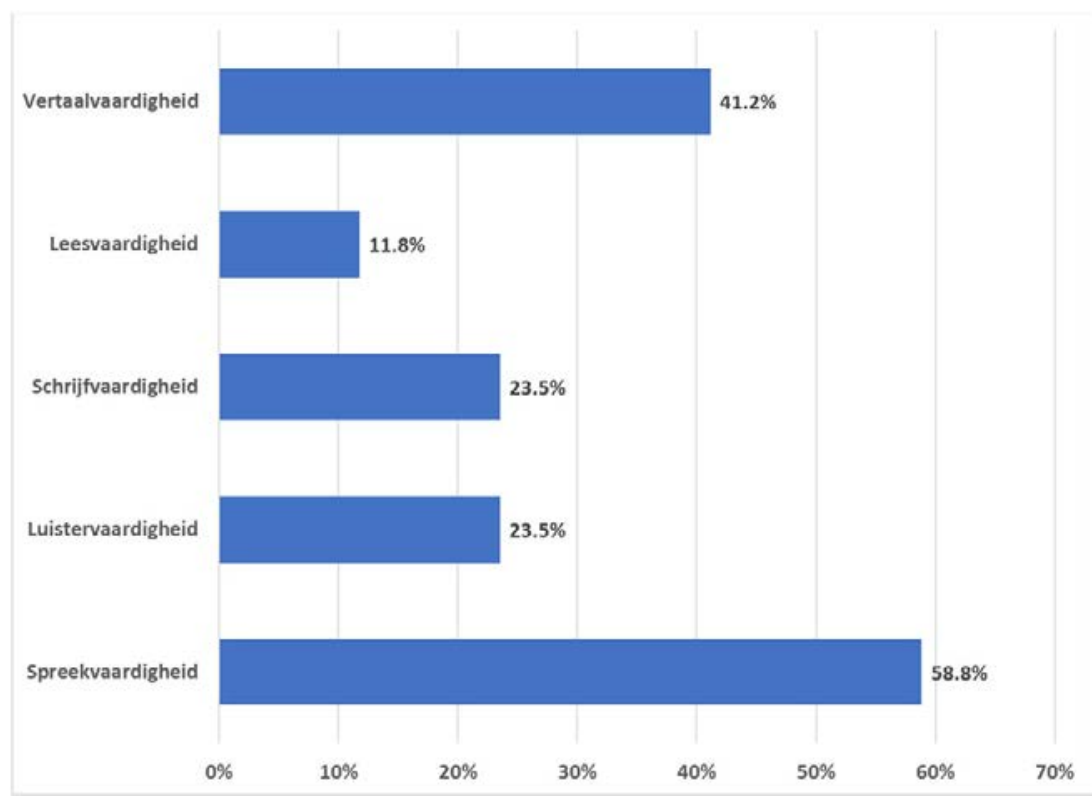

Diagram 4: feedbacksessies: vooruitgang per domein

De laatste reeks vragen (cfr. vraag 12, 13 en 14) hielden verband met het nut van de filmvertaling als voorbereiding op het beroep van vertaler, en in het bijzonder met de kennismaking met de verschillende fasen van vertaalproces en met de omstandigheden waarin een vertaler moet werken. De resultaten van deze vragen werden opnieuw gegroepereerd in één diagram (cfr. diagram 5).

11. Vond je het werken met een reële vertaalopdracht nuttig als voorbereiding op je beroepsleven?

Het gemiddelde antwoord op deze vraag bedroeg 6.4/10 (cfr. diagram 5: professionele leven). Op deze vraag gaven enkele studenten extra commentaar:

- Het is een heel goede oefening.

- Voor degene die in de toekomst vertaler wil worden vind ik deze opdracht interessant en nuttig. Persoonlijk wil ik geen vertaler worden maar $i k$ vind het werken aan dit project interessant en het was leuk om ook iets nieuws/ anders te doen.

12. Vond je het werken met een reële vertaalopdracht nuttig om inzicht te krijgen in het vertaalproces (voorbereiding, vertaling, revisie)?

Voor deze vraag bedroeg het gemiddelde van de antwoorden 7.1/10 (cfr. diagram 5: vertaalproces). Ook op deze vraag gaven enkele studenten commentaar:

- Ja, ik kan zien hoe een reële vertaalopdracht eruitziet.

- Deze oefening heeft mij een inzicht in het werk van vertaler gegeven.

- Ja, ik kan zien hoe een reële vertaalopdracht eruitziet.

- Ook feedback en reële deadlines.

- Ik denk dat student wel een inzicht kan krijgen in het vertaalproces. 
13. Vond je het werken met een reële vertaalopdracht nuttig om bewuster te worden van de omstandigheden waarin een vertaler moet werken?

Het gemiddelde antwoord op deze vraag bedroeg in dit geval 7.7/10 (cfr. diagram 5: werkomstandigheden). Ook deze vraag werd door enkele studenten voorzien van extra commentaar:

- We hebben in een grote groepen gewerkt en daarom ging de samenwerking vlot. Ik denk dat niemand zich belast voelde. Bovendien was het schema met alle deadline's heel handig.

- Ik denk dat het nuttig is om een kans om te werken met een reele vertaalopdracht te krijgen.

- Nuttig!

- Ja, zeker!

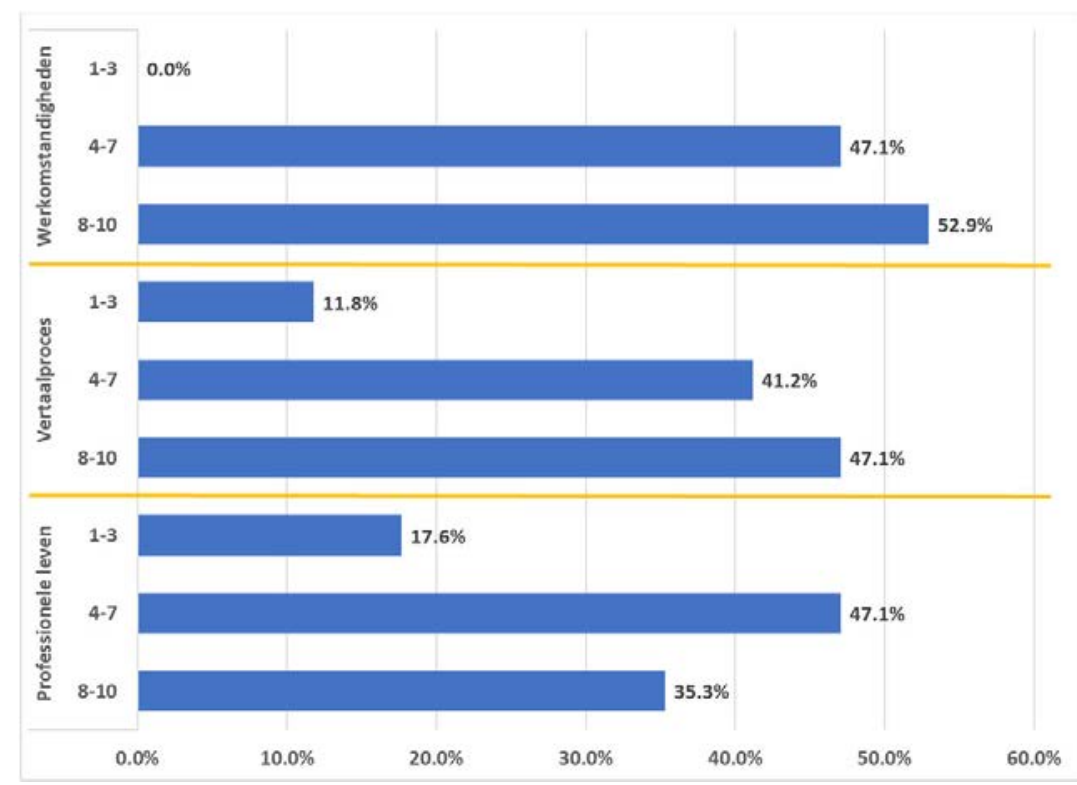

Diagram 5: filmvertaling als voorbereiding op het professionele leven

\section{Conclusie}

In dit onderzoek hebben we gepeild naar de opinie van studenten over 1) vertalen en vertalingen in het vreemdetalenonderwijs, en 2) het werken met reële vertaalopdrachten in de vreemdetaalles. Uit de antwoorden van een enquête die verband hield met deze beide onderzoeksvragen is het volgende gebleken:

- Studenten vinden vertaaloefeningen/communicatieve vertaling belangrijk voor:

- het bevorderen van hun linguïstische vaardigheden: grammatica (zinsbouw), woordenschat en uitdrukkingen (spreektaal); 
- $\quad$ het bevorderen van hun cultuurkennis;

- het bevorderen van hun communicatieve taalvaardigheden: bevordering van de spreekvaardigheid (bijvoorbeeld via interactie/discussie met docent \& medestudenten)

- Studenten vinden het werken met reële vertaalopdrachten nuttig om inzicht te krijgen in de professionele vertaalpraktijk en het vertaalproces.

Uit dit onderzoek blijkt met andere woorden dat vreemdetaalstudenten communicatieve vertaalcolleges met reële vertaalopdrachten waarin voldoende ruimte wordt gemaakt voor gesprek en discussie (cfr. tijdens 'feedbacksessies'), bijdragen tot de bevordering van hun talenkennis (cfr. woordenschat en spreekvaardigheid) en een verdieping van hun inzicht in de reële eisen van de vertaalwereld. Dit onderzoek vormt aldus een aanmoediging om de grenzen tussen vertalen en het taalleren te reduceren, en om grootschaliger onderzoek te verrichten naar de meerwaarde van het vertalen en het werken met reële vertaalopdrachten in het vreemdetalenonderwijs.

\section{Bibliografie}

Carreres, Angeles. 2014. "Translation as a means and as an end: reassessing the divide." The Interpreter and Translator Trainer Volume 8. Issue 1: Translation in the Language Classroom: Theory, Research and Practice. 123-135.

Cook, Guy. 2010. Translation in Language Teaching. Oxford: Oxford University Press.

Council of Europe. 2001. "The Common European Framework Of Reference For Languages: Learning, Teaching, Assessment.” Strasbourg: Language Policy Unit.

Council of Europe. 2017. CEFR Companion Volume. Strasbourg: Language Policy Unit.

Deygers, Bart e.a..2019. Gemeenschappelijk Europees referentiekader voor moderne vreemde talen: leren, onderwijzen, beoordelen. Supplement met nieuwe descriptoren. Den Haag: Taaluniehttp://taalunieversum.org/sites/tuv/files/downloads/ERK\%20-\%20Supplement\%20 met\%20nieuwe\%20descriptoren.pdf [geraadpleegd in juli 2019).

Hervey, Sandor, Ian Higgins, and Louise M. Haywood. 1995. Thinking Spanish Translation: A Course in Translation Method, Spanish to English. Oxon: Routledge.

Kalsbeek, A. van. 2015. "Taalonderwijs en didactiek". Handboek Nederlands als tweede taal in het volwassenenonderwijs. Tweede herziene druk. Bossers, B., Kuiken, F. \& Vermeer, A. (red.). Bussum: Coutinho.

Kiraly, Don. 2000. A Social Constructivist Approach to Translator Education, Manchester: St. Jerome.

Lantolf, James P. (2000) Sociocultural Theory and Second Language Learning, Oxford: Oxford University Press.

Laviosa, Sara. 2014. Translation and Language Education. London and New York: Routledge.

Meijer, Dick, \& José Noijons. 2008. Gemeenschappelijk Europees Refentiekader voor Moderne Vreemde Talen: Leren, Onderwijzen, Beoordelen. Den Haag: Nederlandse Taalunie.http:// taalunieversum.org/sites/tuv/files/downloads/gemeenschappelijk_europees_referentiekader. pdf. (laatst geraadpleegd in juli 2019).

Pym, A., K. Malmkjær \& M. Gutiérrez-Colon Plana. 2013. Translation and Language Learning: The Role of Translation in the Teaching of Languages in the European Union: A Study. Luxembourg: European Commission. https://doi.org/10.2782/13783. 
Vertalen in het vreemdetalenonderwijs? Studenten aan het woord...

Waterlot, Muriel. 2018. Functionele E Taakgerichte Vertaaldidactiek in het Universitaire Vreemdetalenonderwijs, Lublin: Wydawnictwo KUL.

Dr hab. Muriel Waterlot / murielwaterlot@kul.pl.

Katolicki Uniwersytet Lubelski Jana Pawła II, Wydział Nauk Humanistycznych, Katedra Literatury i Języka Niderlandzkiego, Al. Racławickie 14, 20-950 Lublin, PL

This work can be used in accordance with the Creative Commons BY-SA 4.0 International license terms and conditions (https://creativecommons.org/licenses/by-sa/4.0/legalcode). This does not apply to works or elements (such as image or photographs) that are used in the work under a contractual license or exception or limitation to relevant rights 